SISTEMA
ELETRÔNICO
DE REVISTAS
SER I UfPR

\title{
Uma avaliação dos conflitos socioambientais no Núcleo Massambaba do Parque Estadual da Costa do Sol
}

\section{An Evaluation of Social and Environmental Conflicts in Center Massambaba of Costa do Sol State Park}

\author{
Graziele Noronha SANTOS $^{1 *}$, Sérgio Ricardo Silveira BARROS ${ }^{1}$, Ricardo França SANTOS ${ }^{1}$ \\ ${ }^{1}$ Universidade Federal Fluminense (UFF), Niterói, RJ, Brasil. \\ *E-mail de contato: gnoronha@id.uff.br
}

Artigo recebido em 30 de agosto de 2017, versão final aceita em 26 de dezembro de 2017.

RESUMO: O cenário atual da zona costeira no Brasil é de aumento na densidade demográfica, aliada a uma diversificada matriz de atividades econômicas. Nesse cenário, as atividades turísticas e o uso urbano do litoral do município de Saquarema (RJ) são muito semelhantes à realidade do país. A área de estudo é o Núcleo Massambaba do Parque Estadual da Costa do Sol (PECS), limitada ao município de Saquarema e seu entorno, onde foram mapeados os principais conflitos socioambientais relacionados à integridade do Parque, a partir da questão mais crítica na área, que é a urbanização inadequada. O objetivo do trabalho é avaliar os conflitos socioambientais nas áreas adjacentes à Unidade de Conservação fronteiriças ao núcleo Massambaba pelo uso múltiplo do território em que está inserido. Como método, foi realizado um levantamento de dados primários e secundários, os quais foram submetidos às metodologias das matrizes GUT (Gravidade-Urgência-Tendência) e PER (Pressão-Estado-Resposta), com os resultados obtidos analisados por meio da matriz 5W1H, o que possibilitou a proposição de um Plano de Ação para os três maiores problemas encontrados para a área, que são: o não cumprimento dos instrumentos legais voltados ao ordenamento territorial; a inexistência do zoneamento municipal; e a necessidade de maior integração da gestão dos poderes públicos que sobrepõem seus interesses sobre a área. Por fim, apontou-se como o parque pode ter um papel-chave em uma gestão territorial integrada, sobretudo em zonas costeiras.

Palavras-chave: zona costeira; conflitos socioambientais; unidade de conservação.

ABSTRACT: The current scenario of the coastal zone in Brazil shows an increase in population density combined with a diversified array of economic activities. In this scenario the tourist activities and the urban use of the coast of the municipality of Saquarema (RJ) is very similar to the reality of the country. The area of study is the nucleus Massambaba of "Parque Estadual da Costa do Sol - PECS", including Saquarema bounderies 
and their surroundings, where the main social and environmental conflicts mapped were more critical to the integrity of the PECS, starting by the more critical question which is the inadequate urbanization. This paper aims to evaluate the social and environmental conflicts in the adjacent areas of the Conservation Units. The method involved primary and secondary data collection that was subjected to the methodology of matrices GUT (Gravity, Urgency and Tendency) and PER (Pressure, State and Response) with the results analyzed through the 5W1H matrix, which made possible the creation of an Action Plan for the three biggest problems detected in the area, which are: a non-compliance of the legal instruments aimed at territorial planning; the inexistence of the municipal zoning; and the necessity of greater integration of public powers management that overlap their interest in the area. Finally, it was pointed out how the park can play a key role in an integrated territorial management, especially in coastal areas.

Keywords: coastal area; social and environmental conflicts; conservation unit.

\section{Introdução}

A zona costeira é uma área de transição e interação entre litosfera, atmosfera e hidrosfera salgada e continental. Além das interações da zona costeira entre o mar, o ar e a terra é importante ressaltar que as atividades humanas também afetam esta dinâmica. Sendo assim, a melhor interpretação desse espaço é aquela que reconhece e assume a interação entre as atividades humanas e o suporte físico natural como explicação das mudanças que se produzem (Barragán, 2016).

Sabe-se que em todo o mundo a densidade demográfica segue aumentando, principalmente na franja litorânea, e no Brasil não é diferente, já que vem ocorrendo desde a colonização devido à facilidade locacional para o comércio e devido ao seu elevado potencial econômico (Freitas, 2008). Ressalta-se que cerca de $80 \%$ da população no Estado do Rio de Janeiro reside em sua Zona Costeira (INEA, 2015).

De acordo com Andrade (2008), a valorização da zona costeira, por todas as suas condições e características, levou ao aumento vertiginoso de sua ocupação e de seus usos, que, consequentemente, originaram os mais diversos tipos de disputas e conflitos pelos mais variados grupos de atores sociais. Esse diversificado uso histórico da zona costeira gerou um processo de parcelamento acelerado do solo.

O grande impacto do capital imobiliário no litoral e a consolidação do veraneio como política de consumo tiveram ainda como fatores impulsionadores o financiamento imobiliário e a efetiva ligação das regiões litorâneas do Estado à metrópole por meio de obras de infraestrutura, bem como a doação de lotes pela prefeitura de Saquarema em meados da última década de 70 . O surgimento da atividade de veraneio com impacto da "segunda residência", visível em todo litoral brasileiro, levou à urbanização crescente e desordenada, sem a necessária infraestrutura básica de saneamento, abastecimento de água e de um local para disposição final dos resíduos sólidos (Barros et al., 2006). O fenômeno do veraneio continua crescendo no município nas localidades de Vilatur e Nova Itaúna, ambas no entorno da unidade de conservação objeto do estudo.

Foi nesse arcabouço que por meio do Decreto Estadual 9.529, de 15 de dezembro de 1986 (Rio de Janeiro, 1986 - D.O. de 31/01/87), foram criadas a Reserva Estadual Ecológica de Jacarepiá e a Área de Proteção Ambiental de Massambaba, com o 
objetivo de proteger as áreas de preservação permanente (APP) no município de Saquarema (RJ), como a própria lagoa de Jacarepiá e os ecossistemas associados a ela, que naquela época já começava a ser pressionada pela expansão urbana caracterizada principalmente pelo veraneio. Em 2011, 25 anos após a criação dessas áreas protegidas, a Reserva de Jacarepiá foi recategorizada e a Área de Proteção Ambiental (APA) de Massambaba foi sobreposta aos limites que compreendem o Parque Estadual da Costa do Sol. O parque divide-se em quatro setores (Núcleos Atalaia-Dama Branca, Massambaba, Pau-Brasil e Sapiatiba) ao longo de seis municípios (Araruama, Armação dos Búzios, Arraial do Cabo, Cabo Frio, Saquarema e São Pedro da Aldeia).

Nesse sentido, o trabalho se justifica pela importância de se estudar com melhor atenção e profundidade os conflitos socioambientais, sobretudo quando se desenvolvem na unidade espacial da zona costeira, em decorrência dos diversos usos que ocorrem nesta faixa do território e que trazem consigo grandes movimentos de capitais e pessoas onde estão estabelecidas, afetando as dinâmicas naturais e socioambientais tradicionais, isto é, sobrepondo interesses difusos.

Assim, o objetivo do estudo é avaliar os conflitos socioambientais nas áreas adjacentes ao Núcleo Massambaba do Parque Estadual da Costa do Sol, compreendido no município de Saquarema (RJ). Para se alcançar este objetivo, foi realizado um levantamento bibliográfico dos conflitos socioambientais adjacentes às Unidades de Conservação na Zona Costeira, aliado a um levantamento dos aspectos legais pertinentes ao ordenamento territorial. Em uma segunda etapa, utilizou-se o Diagnóstico Rápido Participativo (DRP), a Matriz GUT e a Matriz Pressão-Estado-Resposta (PER) para dar suporte a um plano de ação segundo a metodologia $5 \mathrm{~W} 1 \mathrm{H}$.

\section{2. Área de estudo}

Localizada no Estado do Rio de Janeiro, inserida na Região dos Lagos, atualmente caracterizada como Região Hidrográfica ${ }^{1}$ VI, a área de estudo é o Núcleo Massambaba do Parque Estadual da Costa do Sol, compreendido no município de Saquarema - RJ (Figura 1).

A região da área de estudo é considerada plana, com pequenas elevações, apresentando uma formação de dunas nas proximidades da faixa litorânea, onde predominam praias oceânicas de grande extensão e três importantes sistemas lagunares (Maricá, Saquarema e Araruama). Ressalta-se que o Plano Nacional de Gerenciamento Costeiro II, regulamentado pelo Decreto Federal ${ }^{\circ} 5.300$ de 2004, caracteriza os municípios estuarino-lagunares como de alta relevância para a dinâmica marítima litorânea, como é o caso de Saquarema, Araruama, Arraial do Cabo e Cabo Frio (Brasil, 2004).

Os ecossistemas lagunares presentes ao longo da costa do Estado do Rio de Janeiro apresentam uma grande riqueza biológica e são considerados sistemas de interface que, por um lado, servem de filtro à contaminação oceânica dos materiais de origem continental e, por outro, fornecem nutrientes para a manutenção de cadeias tróficas que abrangem toda a margem continental. É largamente propalada a noção de que o equilíbrio ecológico das

\footnotetext{
${ }^{1}$ O Estado do Rio de Janeiro está dividido para fins de gestão em Regiões Hidrográficas (Resolução CERHI-RJ nº 107, de 22 de maio de 2013), cada qual com o seu comitê de bacia, e o INEA, em conjunto com os comitês e o Conselho Estadual de Recursos Hídricos - CERHI-RJ, trabalha no planejamento dos recursos hídricos.
} 
lagoas costeiras, por ser um criadouro natural para muitas espécies de elevado valor econômico, como crustáceos e peixes, afeta diretamente a atividade pesqueira ao longo da costa (Barroso \& Bernardes, 1995).

Por meio do Decreto Estadual $n^{\circ} 42.929$, de 18 de abril de 2011, foi criado o Parque Estadual da Costa do Sol (PECS), abrangendo uma área total de aproximadamente $9.840,90$ hectares, cada qual composto por uma ou mais áreas distintas, abrangendo parte dos municípios de Araruama, Armação dos Búzios, Arraial do Cabo, Cabo Frio, Saquarema e São Pedro da Aldeia. O PECS é um parque fragmentado, uma vez que abrange 43 áreas protegidas que não estão todas interligadas ao longo dos seis municípios, sendo a primeira UC litorânea do Estado do Rio de Janeiro. O parque também atende a uma das metas estabelecidas pelo Pacto

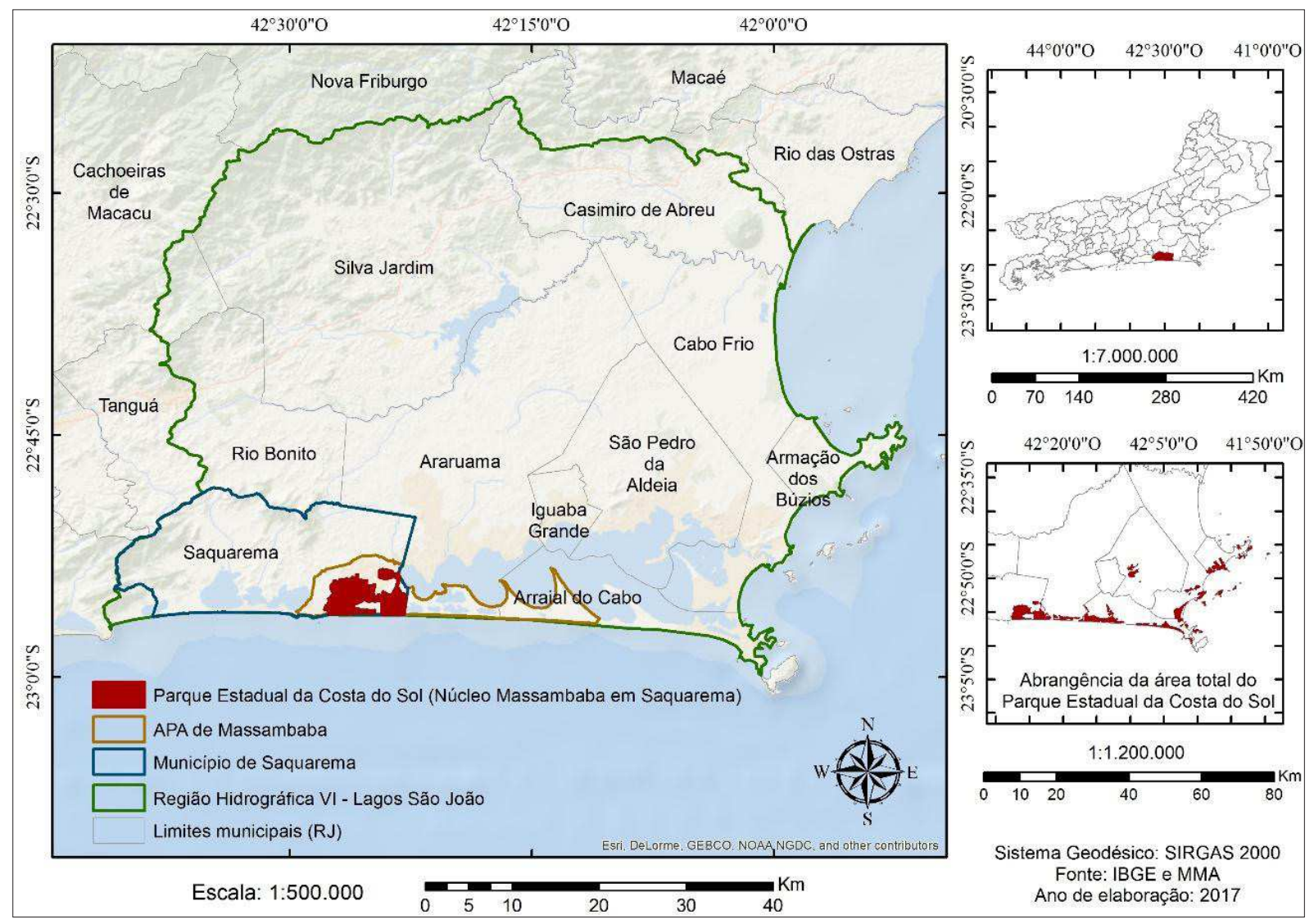

FIGURA 1 - Mapa da área de estudo. FONTE: SANTOS, G. N. 
Ambiental do Sudeste, firmado em outubro de 2007 pelos Secretários de Estado de Meio Ambiente do Rio de Janeiro, de São Paulo, de Minas Gerais e do Espírito Santo, no qual foram estabelecidos compromissos governamentais para o intercâmbio e a união de esforços visando à melhoria das condições ambientais e à promoção do desenvolvimento sustentável no Sudeste (INEA, 2010).

De acordo com o Art. 55 do Sistema Nacional de Unidades de Conservação (SNUC), as unidades de conservação e áreas protegidas criadas com base nas legislações anteriores e que não pertenciam às categorias previstas nesta Lei, a partir de 2000 seriam reavaliadas, no todo ou em parte, no prazo de até dois anos, com o objetivo de definir sua destinação com base na categoria e na função para as quais foram criadas, conforme o disposto no regulamento preconizado. Nesse sentido, a criação do Parque Estadual da Costa do Sol se sobrepôs a duas áreas protegidas que já existiam, a Área de Proteção Ambiental de Massambaba (categoria já prevista no SNUC) e a Reserva Estadual Ecológica de Jacarepiá ${ }^{2}$ (não prevista no SNUC).

AAPA de Massambaba foi criada pelo Decreto Estadual 9.529-C, de 15 de dezembro de 1986, visando regular o uso do solo da região e resguardar ecossistemas remanescentes, como brejos, lagoas costeiras, manguezais e restingas (CALSJ, 2000). Sua localização compreende o litoral da Região das Baixadas Litorâneas, com 26 km de extensão de praias inseridas nos municípios de Saquarema, Araruama e Arraial do Cabo, ocupando uma área total de $76,306 \mathrm{~km}^{2}$. No seu ponto mais estreito possui $700 \mathrm{~m}$ de largura, enquanto o ponto mais largo, incluindo os esporões arenosos que avançam pela Lagoa de Araruama, é de aproximadamente 6 $\mathrm{km}$. AAPA englobava os extensos cordões arenosos que separam a Lagoa de Araruama do mar, além de diversas lagoas menores e pequenas colinas no $\mathrm{Mu}$ nicípio de Saquarema (FEEMA, 2002). Em 21 de setembro de 1999, foi criado um grupo de trabalho, sob a coordenação da FEEMA, para elaborar o Plano de Manejo da APA de Massambaba, concluído no ano de 2002. Este Plano foi subdividido em vários tópicos, cabendo destacar a situação fundiária, os processos de ocupação e os critérios gerais de uso. Em 16 de abril de 2009, o Decreto Estadual de $n^{\circ}$ 41.820 aprovou o Plano de Manejo da Área de Proteção Ambiental de Massambaba.

Ainda, dentro dos limites da APA de Massambaba, foi criada a Reserva Estadual Ecológica de Jacarepiá, de caráter restritivo, com o objetivo de proteger de forma mais restrita as áreas de preservação permanente (APP), como a própria lagoa de Jacarepiá e os ecossistemas associados a ela (Rio de Janeiro, 1986).

\section{Metodologia}

O presente trabalho consiste em um estudo de caso, estratégia que, segundo Yin (2005, p. 26), é utilizada dentro de um enfoque contemporâneo e de um contexto real, em que propõe analisar um conflito, inserido em um tempo e em um espaço, na busca pela evidência de sua problemática, sem manipular comportamentos relevantes.

Este estudo contou com um levantamento dos conflitos existentes em outras UCs e, por meio de um diagnóstico Rápido Participativo (DRP), foram realizadas duas entrevistas semiestruturadas,

\footnotetext{
${ }^{2}$ Resolução CONAMA No 004/1985 - Dispõe sobre definições e conceitos sobre Reservas Ecológicas, categoria não prevista no SNUC.
} 
uma para reconhecimento do local (apoiado em ferramentas de SIG) e outra para entendimento do conflito sob a perspectiva das chefias do Parque Estadual da Costa do Sol e da Área de Proteção Ambiental de Massambaba.

\subsection{Revisão bibliográfica}

O primeiro passo para iniciar este estudo de caso foi realizar um levantamento e uma revisão bibliográfica (utilização de fontes secundárias de informação) sobre os mais diversos casos de conflitos socioambientais presentes em outras Unidades de Conservação no território brasileiro, principalmente nas de zona costeira e, abordando um levantamento documental da legislação local, buscou-se conhecer os conflitos relacionados ao ordenamento territorial da área de estudo.

\subsection{Diagnóstico Rápido Participativo (DRP)}

Petersen \& Romano (1999) mencionam que o Diagnóstico Rápido Participativo (DRP) objetiva proporcionar uma comunicação dialógica entre as comunidades ou grupos sociais que estabeleça um ambiente de discussão e análise dos problemas (conflitos) e que seja possível que diferentes grupos possam expressar suas percepções dos problemas, com vistas a elaborar um plano de ação ou cenários futuros. Neste sentido, esta técnica foi limitada a registrar a percepção dos gestores representantes do PECS e da APA de Massambaba.

Essa ferramenta permite o envolvimento dos atores não apenas como fonte das informações, mas como agentes da pesquisa, e essa mobilização faz com que eles investiguem e analisem suas situações, definam suas prioridades, desenvolvam alternativas e fortaleçam suas capacidades de tomadas de decisão para solucionar problemas e compartilhem seus conhecimentos e experiências com outros (Projeto Rio Sesmaria, 2016).

Como vantagens desta ferramenta, destacam-se o levantamento de informações necessárias e suficientes para uma análise dos grupos sociais existentes; a obtenção de informações de forma rápida, barata e confiável; o compartilhamento com comprometimento das partes por ocasião da análise dos problemas com a comunidade. Por outro lado, tem-se como desvantagens o fato de os grupos sociais apenas responderem por aquilo que acreditam que o técnico queira ouvir, ou se reportarem sobre os problemas que estão os afligindo de imediato, mas não necessariamente os prioritários.

\subsection{Matriz GUT}

A matriz GUT é uma ferramenta que foi desenvolvida por Kepner \& Tregoe (1980) com o objetivo de auxiliar nas decisões complexas que envolvem a resolução de determinados problemas. Ela serve para classificar cada problema e indicar qual deve ter prioridade de solução de acordo com sua gravidade (G), a urgência (U) de resolução e a tendência (T) de piorar de forma lenta ou rápida (Tabela 1).

Enquanto a gravidade é analisada por meio da intensidade ou do impacto que o problema pode causar se não for solucionado, a urgência está relacionada ao tempo disponível para solucionar o problema. Já a tendência do problema tem a ver com a capacidade de evolução (crescimento, redução ou desaparecimento) do problema ao longo do 
tempo. Todas essas três variáveis são avaliadas em uma escala Likert, pontuando de 1 a 5 , conforme indicado na Tabela 1. A partir das avaliações obtidas em entrevistas com os atores mediante a aplicação do DRP, obteve-se o valor final ou nota aferida para cada problema, considerando-se o produto dos pesos atribuídos aos fatores $\mathrm{G}, \mathrm{U}$ e $\mathrm{T}$.

Com a aplicação da matriz GUT no estudo, foi possível obter um panorama dos problemas mais conflitantes da área de estudo com suas tendências futuras e graus de prioridades para tomadas de decisão - que serão elencadas por meio da metodologia Pressão-Estado-Resposta (PER).

\subsection{PER}

Desenvolvido pela Organização para a Cooperação e Desenvolvimento Econômico, a me- todologia Pressão-Estado-Resposta (PER) é um sistema de indicadores, constituído por indicadores de pressão ambiental $(\mathrm{P})$, os quais descrevem as pressões das atividades humanas exercidas sobre o meio ambiente; os indicadores de estado ou condição (E) que se referem à qualidade do ambiente e qualidade e quantidade dos recursos naturais; e os indicadores de resposta $(\mathrm{R})$ que mostram a extensão e a intensidade das reações da sociedade em responder às mudanças e às preocupações ambientais (Vasconcelos et al., 2011).

Baseado no modelo adaptado da PER pelo Programa das Nações Unidas para o Meio Ambiente - PNUMA (2007), entende-se que as pressões (P) sobre o meio ambiente descrevem as pressões das atividades humanas exercidas sobre o meio ambiente pelas suas atividades e processos; o estado (E) do meio ambiente corresponde à sua condição atual,

TABELA 1 - Metodologia da matriz GUT

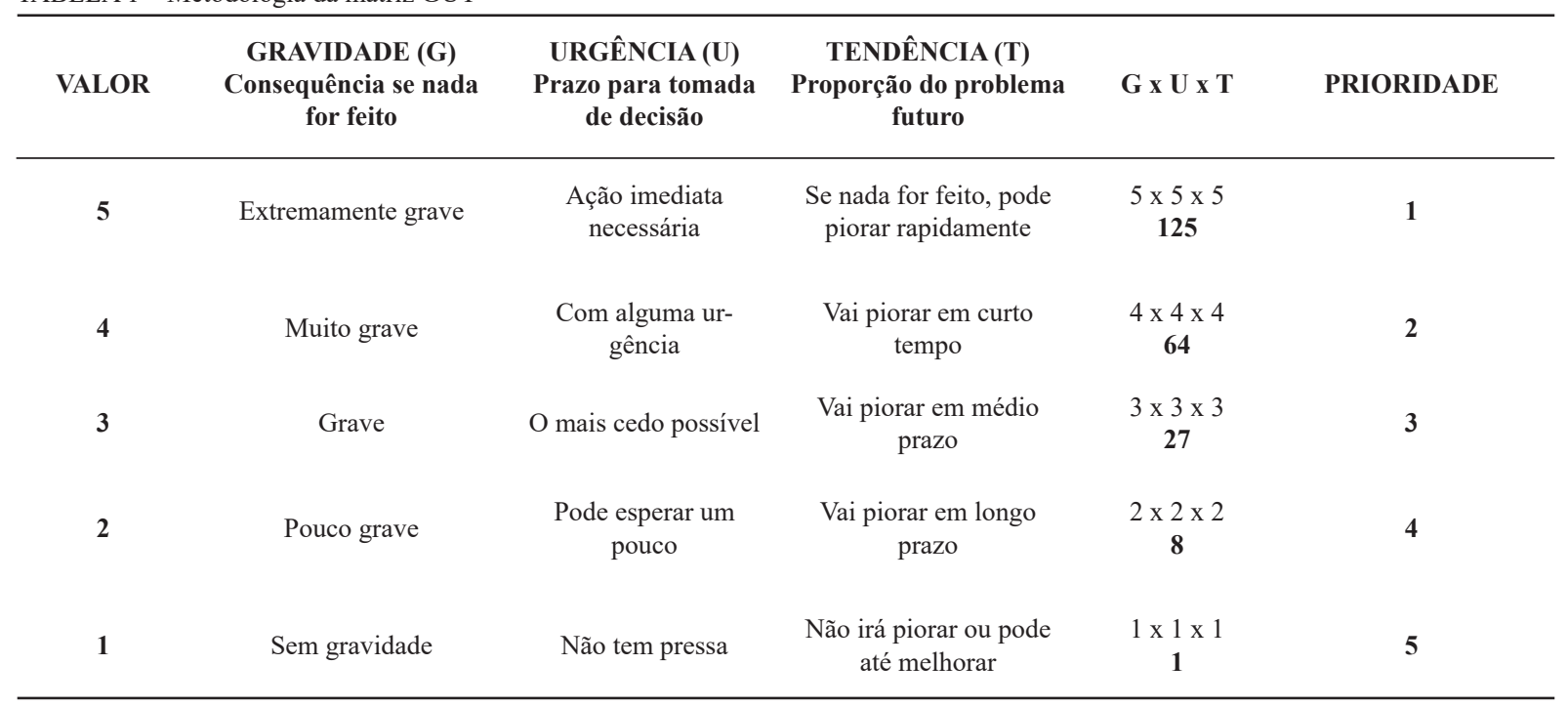

FONTE: Adaptado por Daychoum (2007). 
relacionada com a qualidade ambiental e com os aspectos quantitativos e qualitativos dos recursos naturais; e a resposta $(\mathrm{R})$ corresponde às respostas da sociedade, ações adotadas para mitigar, adaptar, prevenir, deter ou reverter impactos negativos sobre o meio ambiente, produzidos pelas atividades humanas.

De acordo com a proposta de Ribeiro et al. (2012) para o método PER, foram atribuídas notas para a valoração das variáveis $\mathrm{P}, \mathrm{E}$ e R (Tabela 2).

Respeitando a negatividade das notas de pressão e estado, o autor atribuiu valores graduais variando em quatro diferentes escalas, considerando 0 como a melhor nota e 4 como a pior. Já os valores de resposta foram elaborados seguindo a pressuposição de que as ações públicas (respostas) são aplicadas dependendo da situação em que o meio se encontra, considerado este a resultante do decaimento da qualidade ambiental (estado) devido à ação antrópica (pressão), ou seja, as notas atribuídas à resposta dependem especificamente da soma das notas de pressão e estado. A partir da atribuição dessas notas, foi elaborada uma fórmula, representada pela Equação 1, que possibilita calcular a condição ambiental atual, facilitando uma análise das notas da tabela gerada.
Condição Ambiental atual $=$ Resposta $+(-$ Pressão + $(-$ Estado $))$

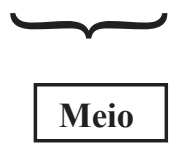

(Equação 1)

Após a elaboração da tabela com as respectivas notas atribuídas, os problemas são evidenciados por meio dos resultados das condições ambientais com maior significância.

\section{5. $5 \mathrm{~W} 1 \mathrm{H}$}

$\mathrm{O}$ método $5 \mathrm{~W} 1 \mathrm{H}$ é utilizado para elaborar planos de ações e permite considerar todas as tarefas a serem selecionadas e executadas de forma cuidadosa e objetiva a fim de serem implantadas organizadamente. A terminologia tem origem nos seis termos da língua inglesa (Tabela 3) e foi adaptado no Brasil, onde é conhecido também como 3Q1POC. O método tem por objetivo levar em consideração os itens que serão expostos a seguir, a fim diagnosticar problemas e planejar soluções.

TABELA 2 - Notas atribuídas ao modelo PER

\begin{tabular}{ccc}
\hline Pressão (-) & Estado (-) & Resposta (+) \\
\hline $4-$ Alta Pressão & $4-$ Altamente Negativa & $8-$ Muito Boa \\
$2-$ Forte Pressão & $2-$ Negativa & $4-$ Boa \\
$1-$ Fraca Pressão & $1-$ Sensível & $2-$ Fraca \\
$0-$ Sem Pressão & $0-$ Positiva & $0-$ Insatisfatória \\
\hline
\end{tabular}

FONTE: adaptado de Ribeiro et al. (2012). 
TABELA 3 - Metodologia 5W1H

\begin{tabular}{cc}
\hline WHAT & O que será feito? \\
WHO & Quem fará? \\
WHEN & Quando será feito? \\
WHY & Por que será feito? \\
HOWE & Onde será feito? \\
\hline
\end{tabular}

FONTE: SANTOS, G. N.

\section{Resultados e discussões}

\subsection{Aspectos legais na territorialidade da área de estudo}

A questão da urbanização inadequada observada na área de estudo remete à exigência da existência de instrumentos e políticas públicas que compatibilizem os usos e ordenem esse território. Quando tais instrumentos não existem ou não são regidos e utilizados de forma eficiente, tem-se a materialização de conflitos, ou seja, os conflitos têm como causa os aspectos ambientais da má gestão e/ou legislações inconsistentes e apresentam como efeito os impactos e os danos aos ecossistemas e à própria sociedade. Os conflitos materializados na área de estudo que puderam ser analisados com base na literatura e observados em campo são, além da expansão inadequada, o desrespeito aos limites da Unidade de Conservação, o desrespeito às Áreas de Preservação Permanente, o não cumprimento dos aspectos legais referentes ao ordenamento territorial, e a inexistência de zoneamento municipal. Todas essas questões que se materializam no espaço territorial refletem a dissonância entre as legislações e políticas de ordenamento territorial do local e a gestão atual.

Entre as políticas públicas de ordenamento de instância municipal encontram-se a Lei Orgânica do Município de Saquarema (PMS, 1990), o Plano Diretor Estratégico - Participativo (PMS, 2006), a Lei de Zoneamento (PMS, 2013b) e a Lei de Parcelamento e Uso do Solo Urbano e Rural (PMS, 2013a) municipal.

Além do Código de Meio Ambiente de Saquarema (PMS, 2010), outras políticas ambientais também fazem regulação territorial e são tangíveis à área de estudo. São elas: o Código Florestal (Brasil, 2012), que faz referência às Áreas de Proteção Permanente - APP, o Sistema Nacional de Unidades de Conservação - SNUC (Brasil, 2000) e a Lei da Mata Atlântica (Brasil, 2006), regulamentada pelo Decreto $n^{\circ} 6.660 / 2008$, que faz referência às áreas de restinga. E ainda, como instrumentos de gestão e ordenamento territorial e exemplos de políticas públicas integradas, faz-se uma ressalva sobre o Zoneamento Ecológico-Econômico da região, o Comitê de Bacia Hidrográfica e o Consórcio Intermunicipal Lagos São João.

\subsection{Ferramentas de análise}

O Diagnóstico Rápido Participativo utilizado neste trabalho foi baseado em uma entrevista semiestruturada com base na proposta de modelo de gestão de um documento do Ministério do Meio Ambiente chamado "Lições aprendidas sobre eta- 
pa de planejamento em plano de manejo de UC" (MMA, 2013). Ele foi aplicado junto aos dois gestores dos respectivos Parque Estadual da Costa do Sol e da APA de Massambaba durante a visita de campo à sede provisória do PECS, ocorrida em julho de 2016, no município de Cabo Frio (RJ).

$\mathrm{O}$ administrador do parque contou um pouco sobre o histórico das UCs e confirmou que o maior conflito no local é decorrente da urbanização inadequada, que exerce pressão sobre as áreas protegidas. Quanto à regularização fundiária dentro dos limites do PECS, $87 \%$ de sua área já foi mapeada, contudo, o zoneamento do Parque ainda não ocorreu justamente por dificuldades relacionadas à questão das desafetações das áreas, as quais tendem a ter seus territórios incluídos na área do Parque.

A gestão compartilhada foi outro ponto apontado pelo entrevistado como uma forma de mitigar determinadas debilidades. O gestor do PECS mencionou a existência de uma política interna para buscar parcerias que ainda não são efetivas justamente porque não há um diálogo entre todos os municípios. Um dos objetivos seria a gestão conjunta entre estes municípios, mas há dificuldades para institucionalizar a participação dos seis municípios envolvidos devido a conflitos entre as instâncias, somado ao fato de o Parque abranger 43 fragmentos. $O$ gestor da APA apontou ainda que a falta de infraestrutura dificulta o trabalho de fiscalização e que a gestão compartilhada seria uma forma de mitigar, por exemplo, essa questão. Ambos acreditam que falta uma Política de Estado.

Segundo informações do gestor do Parque, o Plano de Manejo do PECS encontra-se 60\% elaborado e já conta com a demarcação física que aguarda, no momento, recursos financeiros do Executivo para ser implantada. O gestor do PECS reforçou que há algumas áreas de intenso povoamento urbano (aproximadamente 400 residências) e que elas ainda serão retiradas dos limites do Parque.

Além disso, foi comentado que o Conselho Consultivo do PECS (oriundo do Conselho das APA) é um grande espaço de análise dos problemas e construção de projetos junto à gestão do Parque e que estes podem vir a se tornar Políticas Públicas.

Por meio dos levantamentos de dados primários das visitas de campo, da análise de imagens de satélite e ortofotos, do levantamento documental da legislação e do Diagnóstico Rápido Participativo, foi possível mapear os conflitos socioambientais mais críticos para a região, entre os quais estão a expansão urbana inadequada; o desrespeito aos limites da UC; desrespeito às APPs; o descumprimento dos aspectos legais de ordenamento territorial e a não incorporação das áreas protegidas no zoneamento municipal. Esses conflitos foram submetidos à matriz de criticidade GUT a fim de se obter um panorama de suas tendências futuras e graus de prioridades para tomadas de decisão (Tabela 4).

A Figura 2 apresenta uma imagem aérea de 1970 com sobreposição dos limites da antiga Reserva Estadual Ecológica de Jacarepiá. Percebe-se que nesta ocasião o local ainda se encontrava conservado, sem intervenção urbana, mas já recebia a Estrada dos Cajueiros, que pode ser observada na Figura 3.

A partir do mapa da Figura 4, é possível observar como ocorre atualmente a pressão urbana nos limites do Parque Estadual da Costa do Sol: de oeste para leste com o crescimento do bairro de Nova Itaúna, cujo perfil ainda é marcado pelo veraneio, e de leste para oeste com o crescimento do Distrito de Vilatur, que já se encontrava inserido nos limites internos da unidade de conservação antes de sua recategorização em 2011. Diante da urbanização que 
já não respeitava suas delimitações, visualizadas por meio dos loteamentos e construções inadequadas na parcela do solo que deveria estar protegida, a recategorização da Reserva Estadual Ecológica de
Jacarepiá no Núcleo Massambaba do Parque Estadual da Costa do Sol optou por excluir a região de Vilatur de seus limites. Não obstante, ela continua exercendo pressão sobre a UC.

TABELA 4 - Matriz GUT gerada para os conflitos socioambientais da área de estudo

\begin{tabular}{cccccc}
\hline CONFLITOS & G & U & T & $\begin{array}{c}\text { TOTAL } \\
\text { GxUxT }\end{array}$ & PRIORIDADE \\
\hline Expansão urbana inadequada & 5 & 5 & 4 & 100 & 1 \\
Desrespeito aos limites da UC & 5 & 5 & 4 & 100 & 1 \\
Desrespeito às APPs & 5 & 5 & 4 & 100 & 1 \\
Não cumprimento dos aspectos legais de ordenamento & 4 & 4 & 3 & 48 & 2 \\
Não incorporação das áreas protegidas no zoneamento municipal & 4 & 3 & 3 & 36 & 3 \\
\hline
\end{tabular}

FONTE: SANTOS, G. N.

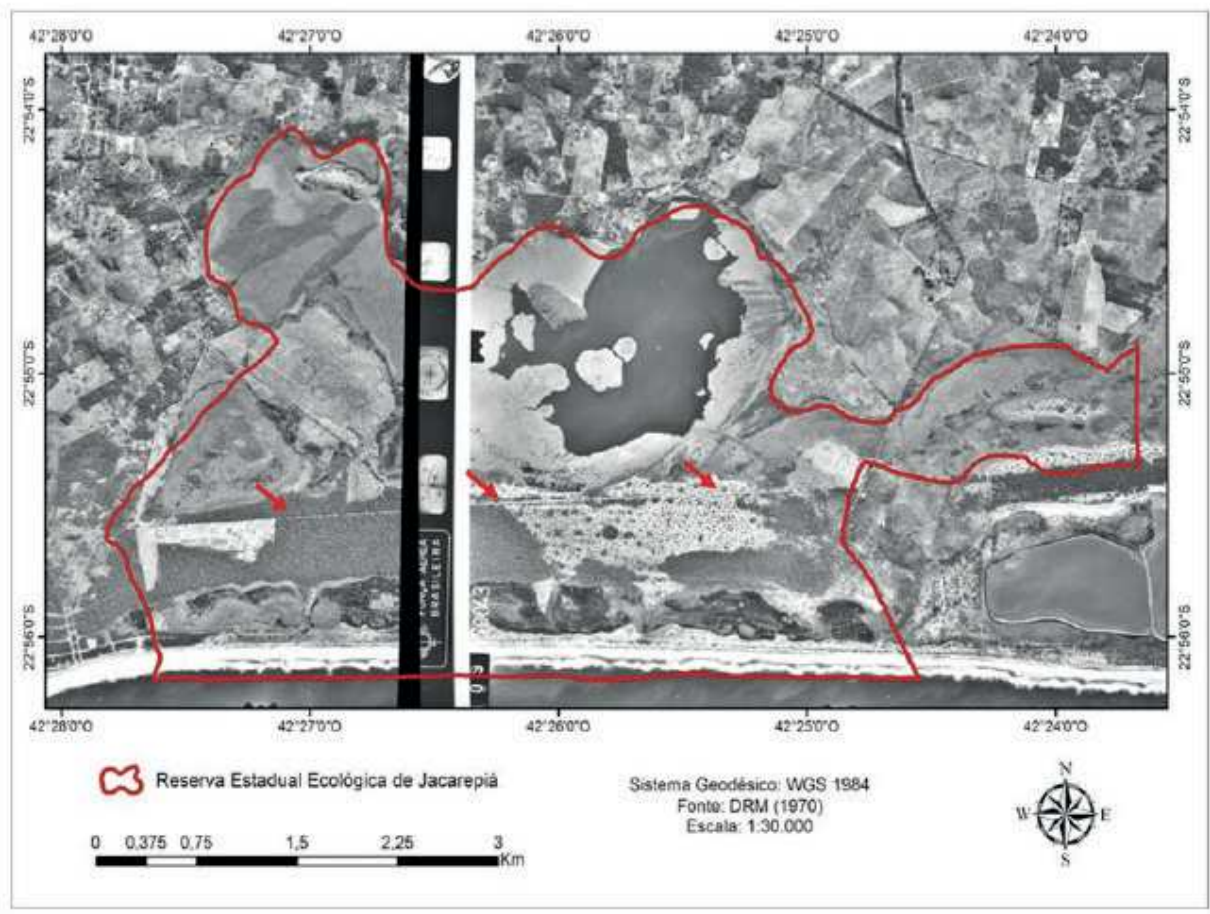

FIGURA 2 - Imagem aérea de 1970 com sobreposição da área que em 1986 (esquerda) foi transformada na Reserva Estadual Ecológica de Jacarepiá.

FONTE: DRM, adaptado por SANTOS, G. N. 


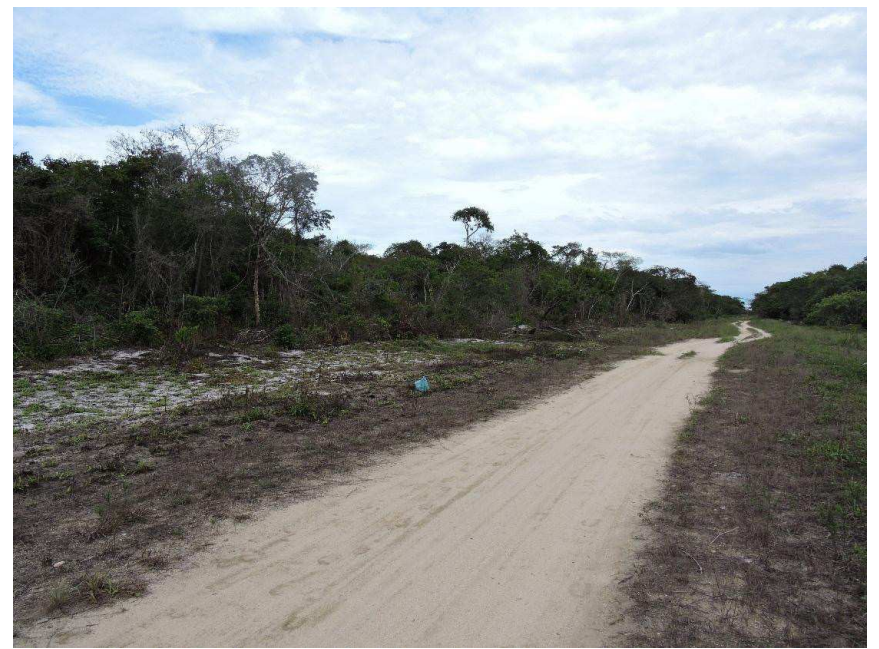

FIGURA 3 - Estrada dos Cajueiros, que corta a unidade de conservação registrada em 2016. FONTE: SANTOS, G. N.

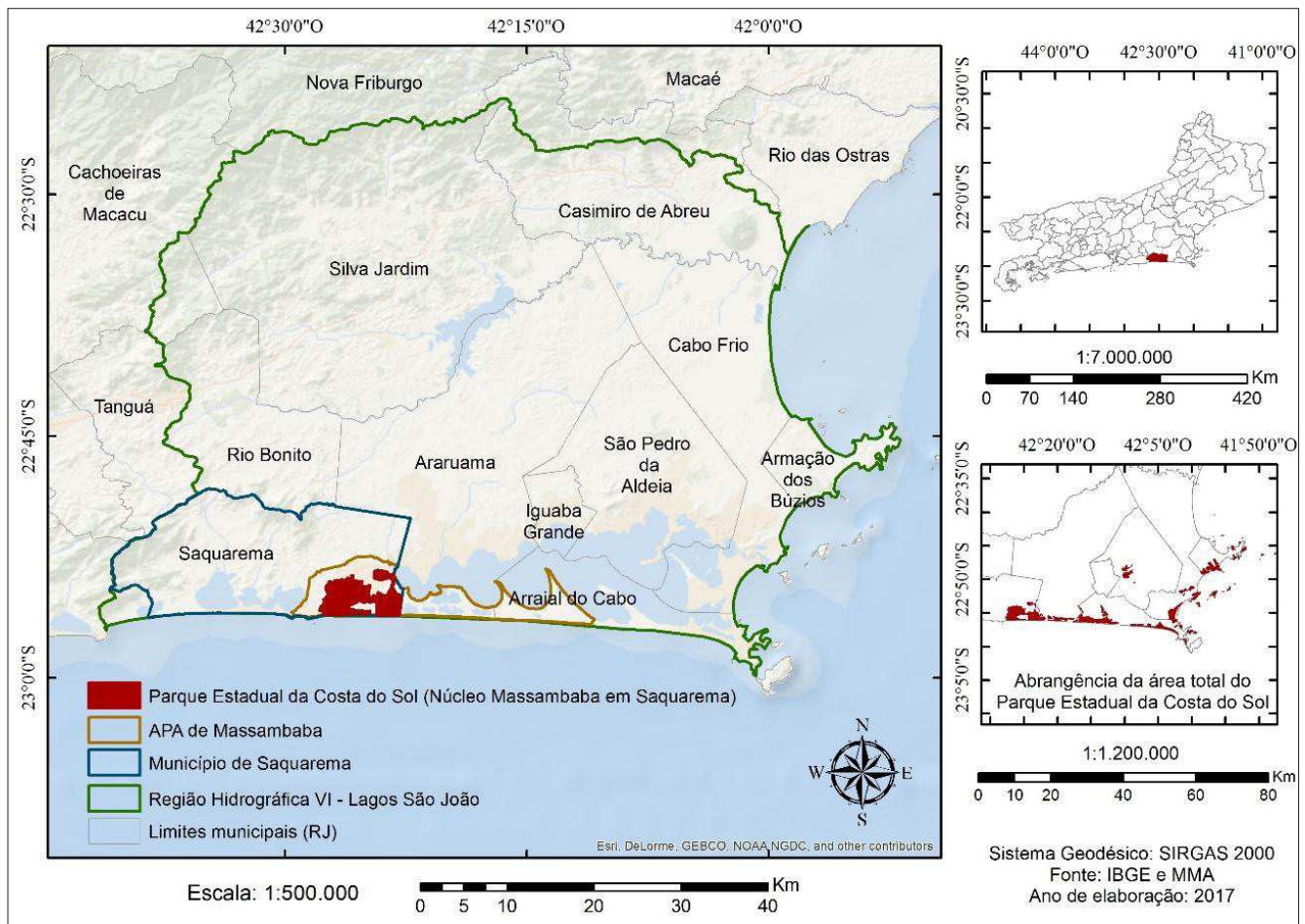

FIGURA 4 - Pressão urbana nos limites do Núcleo Massambaba do Parque Estadual da Costa do Sol.

FONTE: SANTOS, G. N. 
Este quadro ocasionou perdas de área da UC pela supressão da vegetação de restinga para usos particulares (Figura 5), inclusive sobre a faixa marginal de proteção da Lagoa de Jacarepiá, ambas enquadradas como Áreas de Preservação Permanente (APPs) pelo Código Florestal, e da fragmentação dos remanescentes florestais por construções de vias de acesso e serventias para as construções. Ambas as situações também desencadearam o efeito de borda, responsável pela vulnerabilização das áreas que vão se tornando mais expostas e pela fragilização do ecossistema. Todos esses fatores puderam ser constatados pelas observações em campo.
No entanto, se os instrumentos e as políticas públicas que devem compatibilizar os usos e ordenar o território não são eficazes ou muitas vezes nem existem, como é o caso do zoneamento municipal de Saquarema, que só foi aprovado três anos após a criação do PECS, garantir a integridade das áreas protegidas, sejam elas Áreas de Preservação Permanente ou Unidades de Conservação, torna-se uma questão ainda mais complexa e potencial geradora de conflitos.

Nesse contexto, os conflitos socioambientais mapeados anteriormente como mais críticos para a área de estudo encontram-se apresentados na

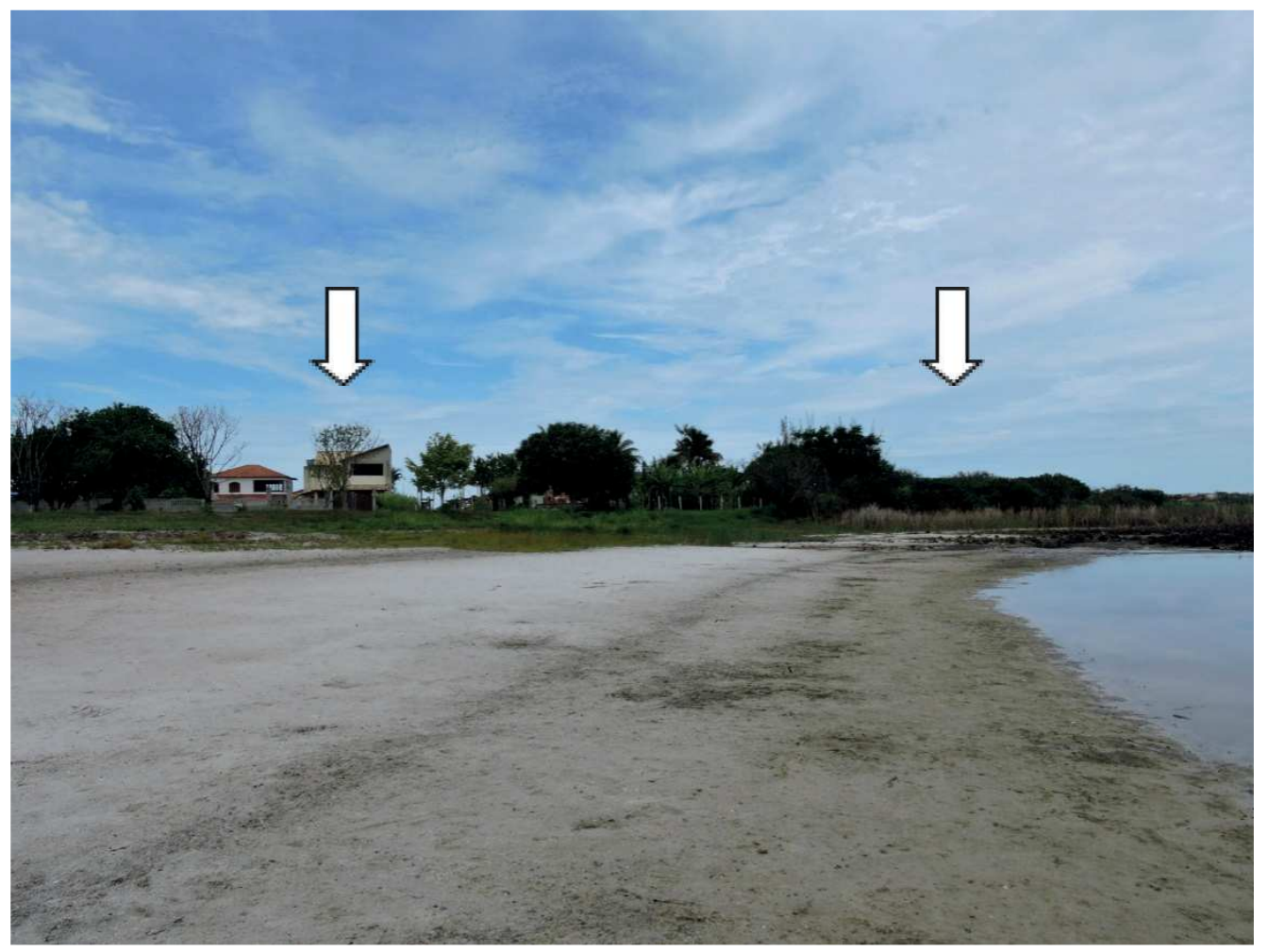

FIGURA 5 - Casas de Vilatur (à esquerda) e a Lagoa de Jacarepiá (à direita), 2016.

FONTE: SANTOS, G. N. 
Tabela 5. A tabela mostra o uso da metodologia Pressão-Estado-Resposta (PER) com a avaliação da condição atual de cada um dos conflitos. Observam-se valores negativos encontrados para a coluna sobre a condição atual.

A expansão urbana inadequada, abordada também por Corrêa e Fontenelle (2012) e que já foi apontada ao longo deste estudo, é o fator de maior criticidade à integridade do Parque Estadual da Costa do Sol, e por isso recebeu a pontuação de -4 tanto para pressão quanto para estado, justamente por oferecer alta pressão sobre o PECS de forma extremamente negativa. Já para a resposta, a pontuação 0 indica que ela tem sido insatisfatória para a resolução do problema, o que pôde ser constatado pelas visitas a campo e pela análise de imagens de satélite confrontadas com as legislações voltadas para o ordenamento territorial local, e principalmente pela entrevista com os gestores do PECS e da APA de Massambaba.

O desrespeito às APPs também está ligado à urbanização inadequada, caracterizada principalmente pela supressão da vegetação de restinga (Figura 4), e por isso também recebeu pontuação de -4 tanto para pressão quanto para estado, oferecendo alta pressão de forma extremamente negativa. A pontuação 0 para a resposta indica que esta tem sido insatisfatória para a resolução do problema, uma vez que a legislação vigente para a garantia dessas áreas protegidas (Plano Diretor e Lei Orgânica) não está sendo cumprida.

O zoneamento municipal também recebeu pontuação -4 para pressão e estado pelos mesmos motivos já citados anteriormente. A pontuação para a resposta foi 0 , tida como insatisfatória, uma vez que ela se apresenta inconsistente, não incorporando as áreas protegidas e não prevendo nenhum tipo de delimitação (memorial descritivo, coordenadas ou mapeamentos) para as Áreas de Interesse Ambiental ou outras áreas específicas, como o PECS.

O desrespeito aos limites das UCs mais uma vez é marcado pela questão da urbanização inadequada (visualizada na Figura 3 e na Figura 4 pelo loteamento entre as setas). Este fato foi apresentado pelos representantes entrevistados, tanto do PECS quanto da APA, como uma das questões mais críticas para a integridade do local, e por isso as pontuações -4 para pressão e para estado. A pontuação de 2 para a resposta indica que as ações para solucionar o problema ainda são fracas, mas não totalmente insatisfatórias como nas anteriores. Embora as legislações voltadas ao ordenamento

TABELA 5 - Matriz PER gerada para os conflitos socioambientais da área de estudo

\begin{tabular}{ccccc}
\hline $\begin{array}{c}\text { INDICADORES } \\
\text { (Conflitos) }\end{array}$ & $\begin{array}{c}\text { PRESSÃo } \\
(-)\end{array}$ & $\begin{array}{c}\text { ESTADO } \\
(-)\end{array}$ & $\begin{array}{c}\text { RESPOSTA } \\
(+)\end{array}$ & $\begin{array}{c}\text { CONDIÇ̃̃o } \\
\text { ATUAL }\end{array}$ \\
\hline Expansão urbana inadequada & -4 & -4 & 0 & -8 \\
Desrespeito aos limites da UC & -4 & -4 & 2 & -6 \\
Desrespeito às APPs & -4 & -4 & 0 & -8 \\
Aspectos legais de ordenamento territorial & -2 & -2 & 2 & -2 \\
Zoneamento municipal & -4 & -4 & 0 & -8 \\
\hline
\end{tabular}

FONTE: SANTOS, G. N. 
territorial da área, como o Plano Diretor e a Lei de Zoneamento, não mencionem nem incluam em nenhum momento tanto o PECS quanto a APA de Massambaba, houve uma reconfiguração dos limites das áreas protegidas com a criação do Parque Estadual da Costa do Sol, justamente para excluir determinadas áreas urbanizadas ou em processo de urbanização dentro dos limites do Parque.

Os aspectos legais de ordenamento territorial receberam a pontuação -2 tanto para pressão quanto para estado, face ao não atendimento às legislações municipais pertinentes ao ordenamento territorial. Já para a resposta, a pontuação 2 indica que ela tem sido fraca para a resolução do problema, uma vez que essas legislações voltadas para o ordenamento do território da área de estudo têm se mostrado inconsistentes, principalmente por não incluírem em nenhum momento o Parque e a APA de Massambaba. Cabe ressaltar que a Reserva de Jacarepiá apenas foi mencionada no Plano Diretor como APP para fins de zoneamento ambiental, e a
Lei Orgânica menciona apenas a Lagoa de Jacarepiá também como APP.

\subsection{Planos de ação}

A partir dos resultados apresentados pela matriz PER, foi gerado um Plano de Ação com o uso da metodologia $5 \mathrm{~W} 1 \mathrm{H}$ para os principais conflitos mapeados para a área de estudo (Tabela 6), que acabam sendo geradores de outros problemas.

A primeira ação que deve ser considerada imediata a ser realizada pelo poder público consiste no cumprimento do ordenamento territorial, proposto tanto pelo Plano Diretor quanto pela Lei Orgânica Municipal e pelo Código do Meio Ambiente, para que a expansão urbana não continue ocorrendo em áreas inadequadas e até mesmo irregulares, tanto sobre as áreas de Unidades de Conservação e suas zonas de amortecimento como sobre as de Área de Preservação Permanente, e que isso seja garantido

TABELA 6 - Demonstração do plano de ação para os principais conflitos socioambientais presentes na área de estudo elaborado a partir a metodologia $5 \mathrm{~W} 1 \mathrm{H}$

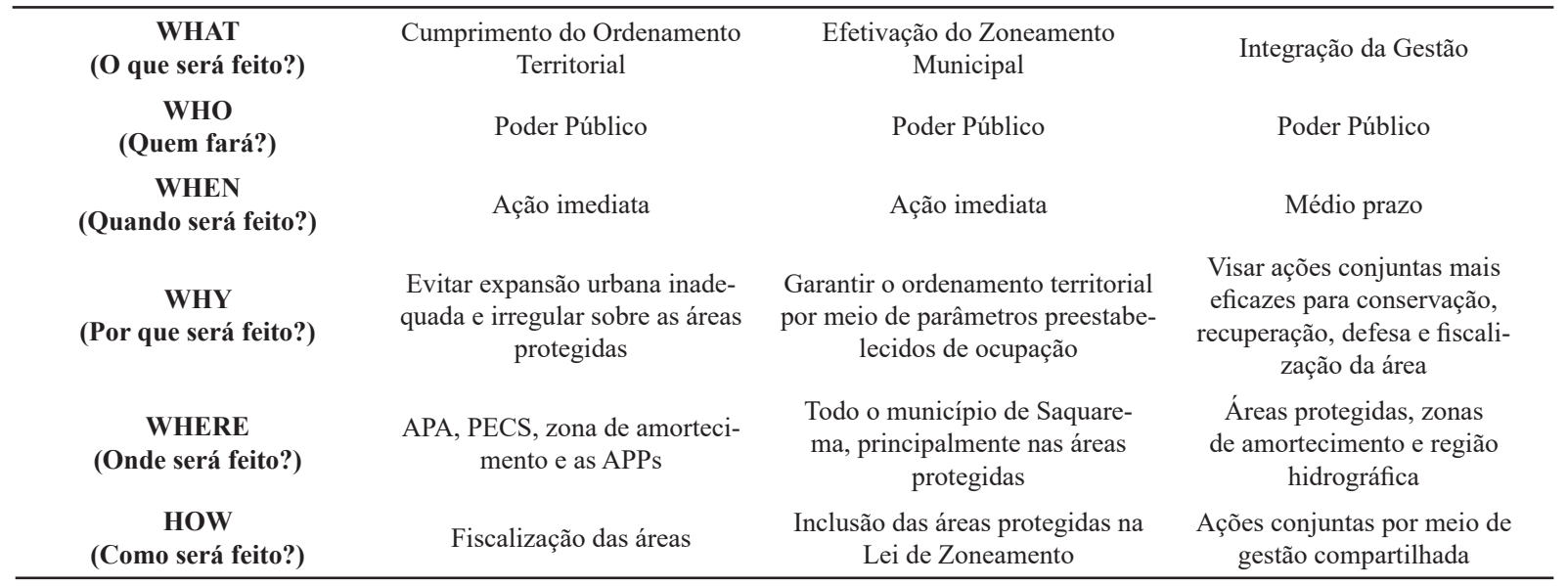

FONTE: SANTOS, G. N. 
por meio da fiscalização, também prevista nas legislações supracitadas.

A segunda ação que também deve ser considerada imediata a ser realizada pelo poder público consiste na inclusão das áreas protegidas no zoneamento do município de Saquarema, principalmente o Parque Estadual da Costa do Sol e sua zona de amortecimento, em consonância com as legislações ambientais, e que esse zoneamento seja revisto e mapeado, por meio de ferramentas de georreferenciamento (SIG). O zoneamento tem como principal objetivo garantir o ordenamento territorial por meio de parâmetros preestabelecidos de ocupação.

Já a terceira ação considerada de médio prazo deve ser realizada pelo poder público, pois consiste na integração da gestão municipal com a gestão da APA de Massambaba e do Parque Estadual da Costa do Sol, sobretudo no que tange à zona de amortecimento, devendo ser efetivamente fiscalizada. Esta atribuição foi constatada no Plano Diretor, ao ser mencionado o texto "maior integração do município com os órgãos ambientais estaduais e federais visando ações conjuntas", e no Art. 22, Capítulos XI e XXIII da Lei Orgânica, quanto à fiscalização e ao controle, além da promoção da associação entre municípios situados na Região dos Lagos.

\section{Conclusão}

Em que pese a limitação da percepção de outros atores, o estudo enalteceu a opinião dos gestores públicos da unidade de conservação devido à recategorização de seu fragmento no município de Saquarema, em 2011, frente à adequação vigente do SNUC.

Verificou-se que a questão mais crítica que ameaça a integridade do Parque é a urbanização inadequada. Baseado no histórico de ocupação da área de estudo e das metodologias aplicadas, foi possível compreender que essa urbanização é desencadeada por três fatores: o não cumprimento dos instrumentos legais voltados ao ordenamento territorial, a inexistência do parque no zoneamento municipal e a necessidade de maior integração da gestão dos poderes públicos que sobrepõem seus interesses sobre a área analisada.

A importância do Gerenciamento Costeiro Integrado neste estudo se dá no que tange à busca pelo equilíbrio das atividades e à minimização dos conflitos relacionados aos interesses do Parque Estadual da Costa do Sol, da Área de Proteção Ambiental de Massambaba, da Prefeitura Municipal de Saquarema e do Comitê de Bacia Lagos São João. Cabe salientar que o Plano de Manejo da APA de Massambaba possui uma instância participativa composta por Câmara Técnica de Revisão do Zoneamento Ambiental e Fiscalização que comtempla atores do Poder Público, da Sociedade Civil Organizada e de Órgãos Setoriais.

As três ações sugeridas por meio da ferramenta de gestão 5W1H utilizada salientaram: (1) o reforço imediato de uma ação fiscalizadora no ordenamento territorial em suas instâncias legais; (2) a incorporação das unidades de conservação no zoneamento municipal de Saquarema; e (3) a integração a médio prazo da gestão do ordenamento territorial municipal com a gestão das unidades de conservação.

\section{Referências}

Andrade, R. I. L. Dinâmicas e conflitos na zona costeira de Aquiraz: Porto das Dunas e Prainha em análise. Fortaleza (CE), Dissertação (Mestrado) - UEC, 2008. 
Barragán, J. M. Política, gestão e litoral: uma nova visão da Gestão Integrada de Áreas Litorais. Madrid, Espanha: Editorial Tébar Flores, 2016.

Barros, S. R. S.; Kersanach, M. W.; Wasserman, J. C. A. Proposta de um Plano de Ação para o Gerenciamento Integrado da Zona Costeira no Município de Saquarema - RJ. Gestão Costeira Integrada, 4(6), 25-32, 2006.

Barroso, L. V.; Bernardes, M. C. Um patrimônio natural ameaçado: poluição, invasões e turismo sem controle ameaçam lagoas fluminenses. Ciência Hoje, 19, 70-74, 1995.

Brasil. Lei $n^{\circ}$ 7.661, de 16 de maio de 1998. Institui o Plano Nacional de Gerenciamento Costeiro. Brasília: DOU de 18/05/1998.

Brasil. Lei $n^{\circ}$ 9.985, de 18 de julho de 2000. Institui o Sistema Nacional de Unidades de Conservação da Natureza - SNUC. Brasília: DOU de 19/07/2000.

Brasil. Decreto $n^{\circ}$ 5.300, de 07 de dezembro de 2004. Regulamenta a Lei ${ }^{\circ} 7.661$ de 16 de maio de 1988, que institui o Plano Nacional de Gerenciamento Costeiro - PNGC. Brasília: DOU de 08/12/2004.

Brasil. Lei $n^{\circ} 11.428$, de 22 de dezembro de 2006. Dispõe sobre a utilização e a proteção da vegetação nativa do Bioma Mata Atlântica. Brasília: DOU de 22/12/2006.

Brasil. Lei $n^{\circ} 12.651$, de 25 de maio de 2012. Dispõe sobre o Código Florestal Brasileiro. Brasília: DOU de 28/05/2012.

CALSJ - Consórcio Intermunicipal Lagos São João. Estatuto, 2000. Disponível em: <http://www.lagossaojoao.org. br/index-1.html >. Acesso em: out. 2016.

Corrêa, W. B.; Fontenelle, T. H. O Parque Estadual Costa do Sol: contextualização e Críticas ao Processo de Instituição. Revista Geonorte, Edição Especial, 3(4), 1150-1160, 2012.

Daychoum, M. 40 ferramentas e técnicas de gerenciamento. 2. ed. Rio de Janeiro: Brasport, 2007.

FEEMA - Fundação Estadual de Engenharia do Meio Ambiente. Área de Proteção da Massambaba - Plano Diretor. Rio de Janeiro: Governo do Estado do Rio de Janeiro/Secretaria de Estado de Meio Ambiente e Projetos Especiais/ FEEMA/Departamento de Planejamento Ambiental - DEP, 2002. p. 79.
Freitas, M. A. P. Zona costeira e meio ambiente. 1. ed., 4. tir. Curitiba: Juruá, 2008.

INEA - Instituto Estadual do Ambiente. INEA discute criação do Parque da Costa do Sol. Publicado em 03/03/2010. Disponível em: $<$ http://www.inea.antigo.rj.gov.br/noticias/ noticia_dinamica1.asp?id_noticia $=712>$. Acesso em: out. 2016.

INEA - Instituto Estadual do Ambiente. Unidades de Conservação: APA de Massambaba. 2015. Disponível em: $<$ http://www.inea.rj.gov.br/Portal/Agendas/BIODIVERSIDADEEAREASPROTEGIDAS/UnidadesdeConservacao/ INEA_008614\#/Informa>. Acesso em: out. 2016.

Kepner, C. H.; Tregoe, B. B. O administrador racional: uma abordagem sistemática para solução de problemas. São Paulo: Atlas, 1980.

MMA - Ministério do Meio Ambiente. Lições aprendidas sobre o Diagnóstico para Elaboração de Planos de Manejo de Unidades de Conservação - Comunidade de Ensino e Aprendizagem em Planejamento de Unidades de Conservação. Brasília: WWF-Brasil, 60 p. 2013.

Petersen, P.; Romano, J. O. Abordagens participativas para o desenvolvimento local. Rio de Janeiro: AS-PTA/Actionaid - Brasil, 1999. 144 p.

PMS - Prefeitura Municipal de Saquarema. Lei Orgânica Municipal de Saquarema de 5 de abril de 1990.

PMS - Prefeitura Municipal de Saquarema. Lei $N^{\circ} 848$, de 10 de outubro de 2006. Dispõe sobre o Plano Diretor Estratégico - Participativo do Município de Saquarema.

PMS - Prefeitura Municipal de Saquarema. Lei $N^{o} 1.055$, de 19 de março de 2010. Dispõe sobre o Código Municipal de Meio Ambiente do Município de Saquarema.

PMS - Prefeitura Municipal de Saquarema. Lei $N^{o} 1.293$, de 07 de outubro de 2013a. Dispõe sobre o Parcelamento do Solo Urbano e Rural no Município de Saquarema, Estado do Rio de Janeiro.

PMS - Prefeitura Municipal de Saquarema. Lei $N^{o} 1.294$, de 07 de outubro de 2013b. Dispõe sobre o Zoneamento do Município de Saquarema, Estado do Rio de Janeiro.

PNUMA - Programa das Nações Unidas para o Meio Am- 
biente. Projeto GeoCidades: relatório ambiental urbano integrado - Rio de Janeiro. Rio de Janeiro: PNUMA/MMA/ IBAM/ISER/REDEH, 2007.

Projeto Rio Sesmaria. Recuperação Ambiental da Sub-bacia do Rio Sesmaria: diagnóstico físico e socioambiental e implantação de unidades demonstrativas. Diagnóstico Rápido Participativo. Disponível em: <http://crescentefertil.org.br/ projetoriosesmaria/site/wp-content/uploads/6.-DRP.pdf > . Acesso em: set. 2016.

Ribeiro, A. I.; Vilares, G. N.; Medeiros, G. A.; Junior, V. M.; Lourenço, R. W. Utilização do Modelo Pressão, Estado e Resposta (PER) no Parque Municipal da Água Vermelha "João Cândido Pereira" - Sorocaba-SP. III Congresso Brasileiro de Gestão Ambiental. Goiânia/GO - 19 a 22/11/2012.
Rio de Janeiro. Decreto Estadual 9529-C de 15 de dezembro de 1986. Cria a Área de Proteção Ambiental na Lagoa de Araruama e Praia de Massambaba (APA de Massambaba). Disponível em < http://www.icmbio.gov.br/ cepsul/images/ stories/legislacao/Decretos/1986/dec_9529_1986_apamassambaba_rj.pdf $>$. Acesso em: 20 jun. 2016.

Rio de Janeiro. Decreto $N^{o} 36.722$, de 08 de dezembro de 2004. Institui o Comitê de Bacia Hidrográfica Lagos São João.

Vasconcelos, A. C. F.; Oliveira, J. R. M.; Santos, J. E. A.; Nunes, E. R.; Freitas, G. C. Pressão Estado Impacto Resposta: um estudo em curtumes artesanais na Paraíba. In: Anais do Encontro Internacional sobre Gestão Empresarial e Meio Ambiente - ENGEMA. 2011.

Yin, R. K. Estudo de caso: planejamento e métodos. 3. ed. Porto Alegre: Bookman, 2005. 